\title{
Strategiclnitiatives
}

\section{The MSA Bold Strategic Initiative Funding Program}

\author{
Jay Jerome
}

Chair of the Strategic Initiatives Review Committee

jay.jerome@vumc.org

\begin{abstract}
A new program has been established by the Microscopy Society of America (MSA) to provide funding for bold, new, strategic initiatives that further the goals of the Microscopy Society of America and the fields of microscopy, microanalysis, and imaging in general. Three bold, new initiatives won initial funding for 2019: a proposal to fund an international micrograph competition, an initiative to set up an MSA Student Council web presence to host web events targeted to microscopy students and developing professionals, and a plan to provide a uniform template and hosting service for MSA Local Affiliated Societies.
\end{abstract}

Keywords: Strategic initiative, funding, microscopy, microanalysis, imaging

\section{Introduction}

The 75th anniversary of the Microscopy Society of America (MSA) prompted reflection within the MSA Council on the past and future of MSA. One of the results of this analysis was the establishment in 2018 of a program to fund bold new initiatives in microscopy that enhance the society's mission to "to promote and advance the techniques and applications of microscopy and microanalysis in all relevant scientific disciplines." Funds dispersed through this new program are specifically designed to support new and novel initiatives.

\section{The Application Process}

The initial call for proposals went out in August of 2018. Applicants were encouraged to target one or more of the strategic areas identified by the MSA Council as areas of emphasis. For the 2018 application period (to be funded in 2019), those areas were defined as:

1. Novel initiatives that promote student involvement in microscopy.

2. MSA-branded dissemination of information regarding new advances in microscopy, microanalysis, and image analysis.

3. Enhancement of member benefits leading to retention of members.

4. Leadership training/mentorship to provide future leaders for MSA and the field of microscopy.

5. Initiating or enhancing academic, governmental, and industrial partnerships (excluding microscopy vendors and vendors of

Comments:

Comments:

\section{Summary:}

microscopy-related products) in microscopy application and development.

6. Collection, preservation, and dissemination of microscopyrelated information (technical procedures, basic theories, scientific backgrounds, MSA archived material, etc.).

For the 2018 cycle, applicants could request up to $\$ 15,000$ for one year of funding. The application process required an application of no more than 3 pages describing the strategic initiative and a detailed budget request. Applications were due by December 1, 2018. The principal applicant was required to be an MSA member. The applications were reviewed by a panel of MSA members with a breadth of experience within MSA as well

MSA BOLd STRATEGIC INITIATIVES

REVIEW OF APPLICATION

Title of Application:

Principals involved in initiative:

Brief Summary of Application:

Scoring Rubric:

1-3 Outstanding, 3-5 Very Good, 5-7 Average, 7-9 Poor, 10 No funding

$(30 \%)$ Alignment of the Proposal with MSA Strategic Goals $\quad$ Score:

\begin{tabular}{|l|l|}
\hline$(30 \%)$ Boldness and Innovation of the Proposal & Score: \\
\hline
\end{tabular}

\begin{tabular}{|l|l|}
\hline (30\%) Importance of the Proposal to MSA Strategic Goals & Score: \\
\hline
\end{tabular}

\section{Comments:}

(10\%) Feasibility of Success of Proposal Goals

Score:

Comments:

Overall Evaluation

Summary Score:

Figure 1: Scoring sheet used by reviewers to critique the Strategic Initiatives proposals. 


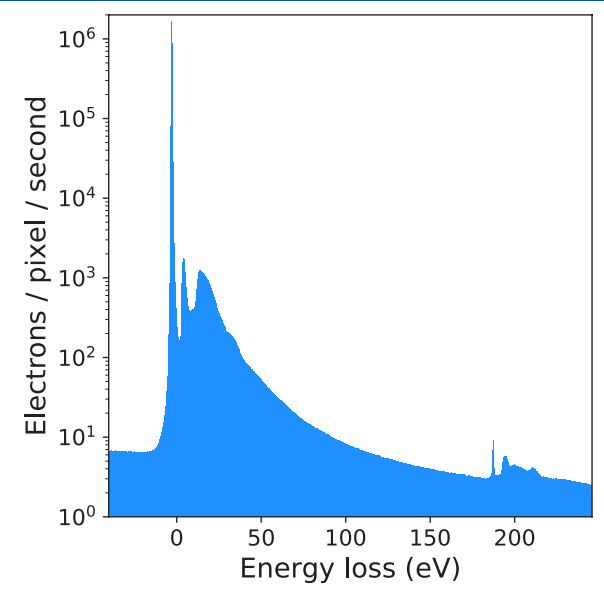

EELS of hexagonal boron nitride ( $h-B N)$. $E_{0}=100 \mathrm{keV}$, beam current=170 pA, 10 s exposure, $0.28 \mathrm{eV} / \mathrm{ch}$. Raw data (no dark subtraction or gain normalization).
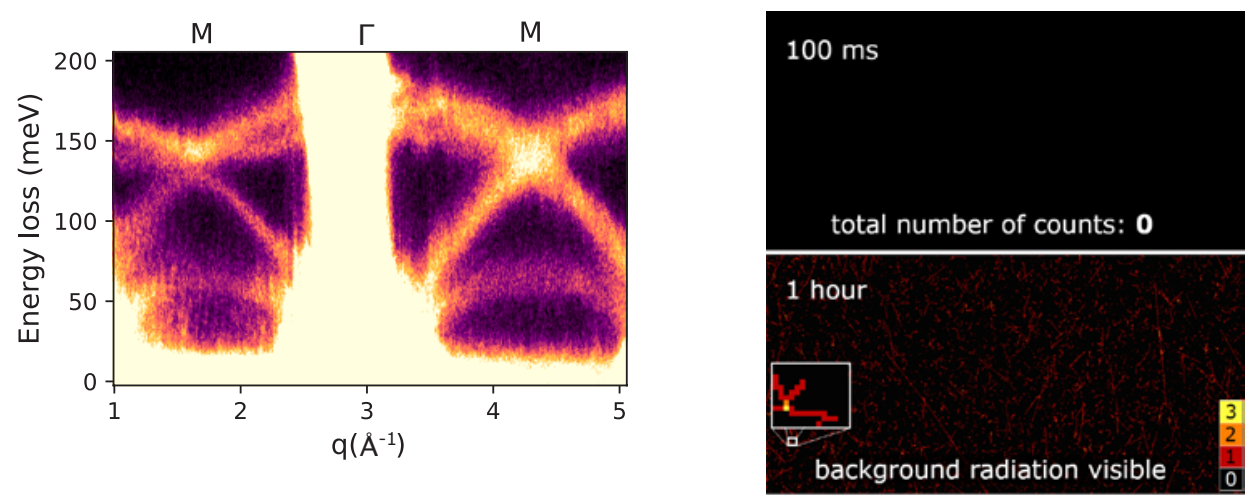

Momentum-resolved EELS of h-BN showing phonon Detector sensitivity test with no signal. Top: With dispersion curves $S(q, \omega)$ acquired in 6.7 minutes short exposure times, there is no background. (100 frames $\times 4$ seconds, aligned) using a slot ent- Bottom: With long exposure times, cosmic rays (typirance aperture. $E_{0}=60 \mathrm{keV}$, beam current=10 pA, cally muons) are detected. energy resolution $10 \mathrm{meV}$.

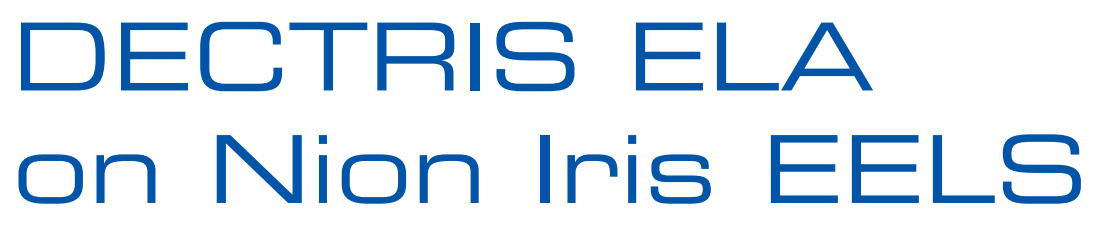

A new direct detector
for 30 -200 keV EELS

\section{DECTRIS hybrid pixel detector}

- 1030 x 516 pixels of $75 \mu \mathrm{m}$ each

- 2,250 full frames/s and faster for sub-areas

- PSF @ 100 keV 1.3 pixels, better at lower keV

- DQE 0.8 (without super-resolution)

- Dynamic range > 106:1

- Can use >100 pA while counting single electrons

- Optimized for 30-200 keV operation 


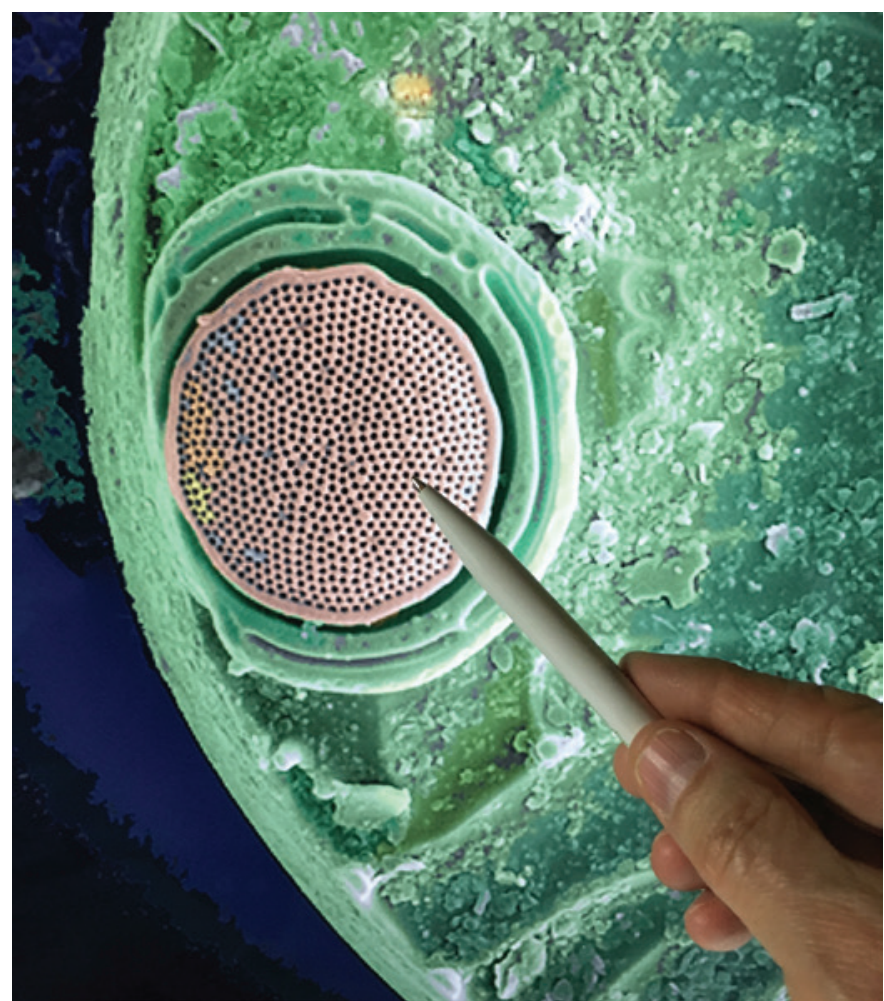

Figure 2: Judging of an image submitted to the 2019 Microscopy Today Micrograph Awards competition.

as in the fields of microscopy, microanalysis, and imaging. The review criteria included alignment of the proposal with the published areas of emphasis, importance of the program to MSA's mission, innovation of the proposal, and feasibility of success (Figure 1). The committee's recommendations were then provided to the MSA Council for final decisions on funding.

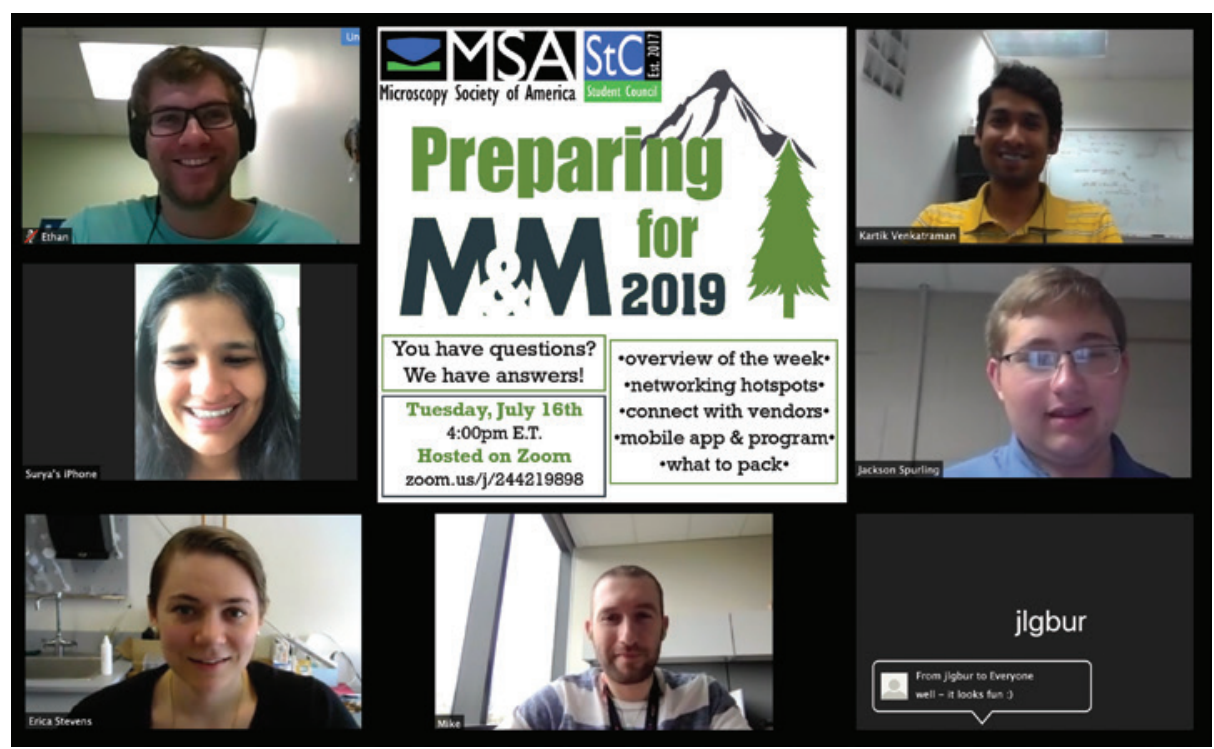

Figure 3: MSA Student Council was awarded funds to host professional development and communitybuilding events via the Zoom webinar platform. The platform allows participants to join via a web browser, mobile application, or by telephone. The platform allows the community to stay connected and grow together throughout the year without the need for a plane ticket.

\section{Initiatives Receiving Funding in 2019}

Three proposals won funding in the initial cycle. Funding began in February of 2019. Among the proposals funded was a proposal by Charles Lyman and Robert Simmons to fund a formal international micrograph competition branded jointly by MSA and Microscopy Today. The Microscopy Today Micrograph Awards competition is described in this issue's From the Editor column by Charles Lyman, Editor-in-Chief. Micrographs for the competition could be submitted in one of three categories: (1) Published images, (2) Open (unpublished images), and (3) Video images. The Published category represents micrographs published for the first time in 2018 in any reputable publication and for which permission for use has been granted. The Open category is for unpublished micrographs from any microscopist anywhere in the world. Finally, the Video category encompasses scientific multi-frame presentations including live imaging, time-lapse sequences, and animation of $3 \mathrm{D}$ reconstructions. Although aesthetics is the most important aspect, the scientific relevance of an image is also a consideration in the judging (Figure 2). The first place award in each category comes with a US $\$ 500$ prize. Second and third place awardees receive US $\$ 300$ and US $\$ 100$, respectively. The contest was widely advertised, and images were submitted from all over the world. The submission period for 2019 closed in February, and the competition judges have selected 25 finalists (see the cover of this issue). A composite video of the finalists will be shown at the M\&M show in the plenary session and in the Cambridge University Press booth during the meeting. The selection panel's celebrity judge, David Scharf (together with Robert Simmons and Charles Lyman), will hold a workshop at $\mathrm{M} \& \mathrm{M}$ on creating images for micrograph competitions. The announcement and presentation of the nine cash award winners will take place at $M \& M$ on Wednesday afternoon at 4:30 p.m. on the stage next to the poster area. The winning micrographs will also be highlighted in the September issue of Microscopy Today.

Funds were also provided to the MSA Student Council to set up and maintain a web presence for conducting Student Council business and providing webinars on career pathways, career development, leadership training, and other topics of interest. These presentations would be hosted by Student Council members or recognized experts on the topic at hand. The Student Council has already presented a webinar on "PhD Pathways Career Panel." This had 20 participants. In mid-May, they hosted a webinar on "Science Communication." The webinar covered how to write and submit a scientific paper and how to present scientific data in a conference presentation. These topics were presented by experts in publishing and presenting scientific data. Realizing that there are differences between the biological and physical sciences for oral presentations, the session also had breakout rooms for discussion of 
the topic from each perspective. In late June, the MSA Student Council hosted "Preparing for M\&M" (Figure 3). This webinar covered how to get the most from the M\&M conference, what to expect, and other similar topics. Because of the interactive platform they have chosen (Zoom), the Student Council can offer the opportunity for webinar attendees to ask questions of those who have previously attended an M\&M conference. The MSA Student Council is working with the M\&M conference planners to create a comprehensive overview and provide "pro tips." Updates, with details, can be found on MSA Student Council social media. Twitter: @MSAStudent, Facebook: @ MSAStudentCouncil.

Finally, Beverly Maleeff was awarded funds to set up a uniform system for MSA Local Affiliated Societies (LAS) to have an MSA-branded web presence. This proposal had the support of most of the MSA Local Affiliated Societies: most were enthusiastic about having an MSA-hosted, uniform, and well-designed window into their society. A template for submitting LAS information will be used to create a display of content from participating local affiliated societies. This is analogous to the way major sports leagues provide a platform for teams within the league. Each team's page has a similar layout but with team-specific logos and color schemes. It is envisioned that this will allow each LAS to have a professional appearance, highlight their affiliation with MSA, and provide a uniform, intuitive experience to those learning about or accessing specific LAS content via the MSA portal at: https://www.microscopy.org/communities/ affiliate_societies.cfm.

\section{The 2019 Strategic Initiatives Competition}

The first year of the program was a huge success with a number of strong proposals receiving funding. Given the success of the first year, the MSA Council has agreed to continue the program. If you have a bold idea, begin planning now to submit a proposal for the 2019 competition. Specific details for the 2019 funding round will be announced in August, soon after the M\&M conference. Applications will be due by November 15, 2019, for funding to begin in 2020. Details of the program and the previous application process are available at https://www.microscopy.org/resources/strategic_initiatives. $\mathrm{cfm}$. This is also where information about the 2019 funding competition will be provided once it is finalized in August. The details to be provided include the maximum amount that can be requested, the application process, and the key MSA goals being targeted for 2020. In general, an application should be $2-3$ pages and address three key points: (1) the MSA Strategic Goal(s) being targeted and how the application addresses these goals; (2) details of the proposed plan, including means for assessing success; and (3) analysis of the innovation and importance of the proposed initiative. In addition, the applicant must provide a detailed budget that breaks down how the funds will be spent.

We encourage all MSA members from around the world to consider submitting an application in the fall. Meanwhile, if you have questions about the program feel free to contact Jay Jerome (jay.jerome@vumc.org).

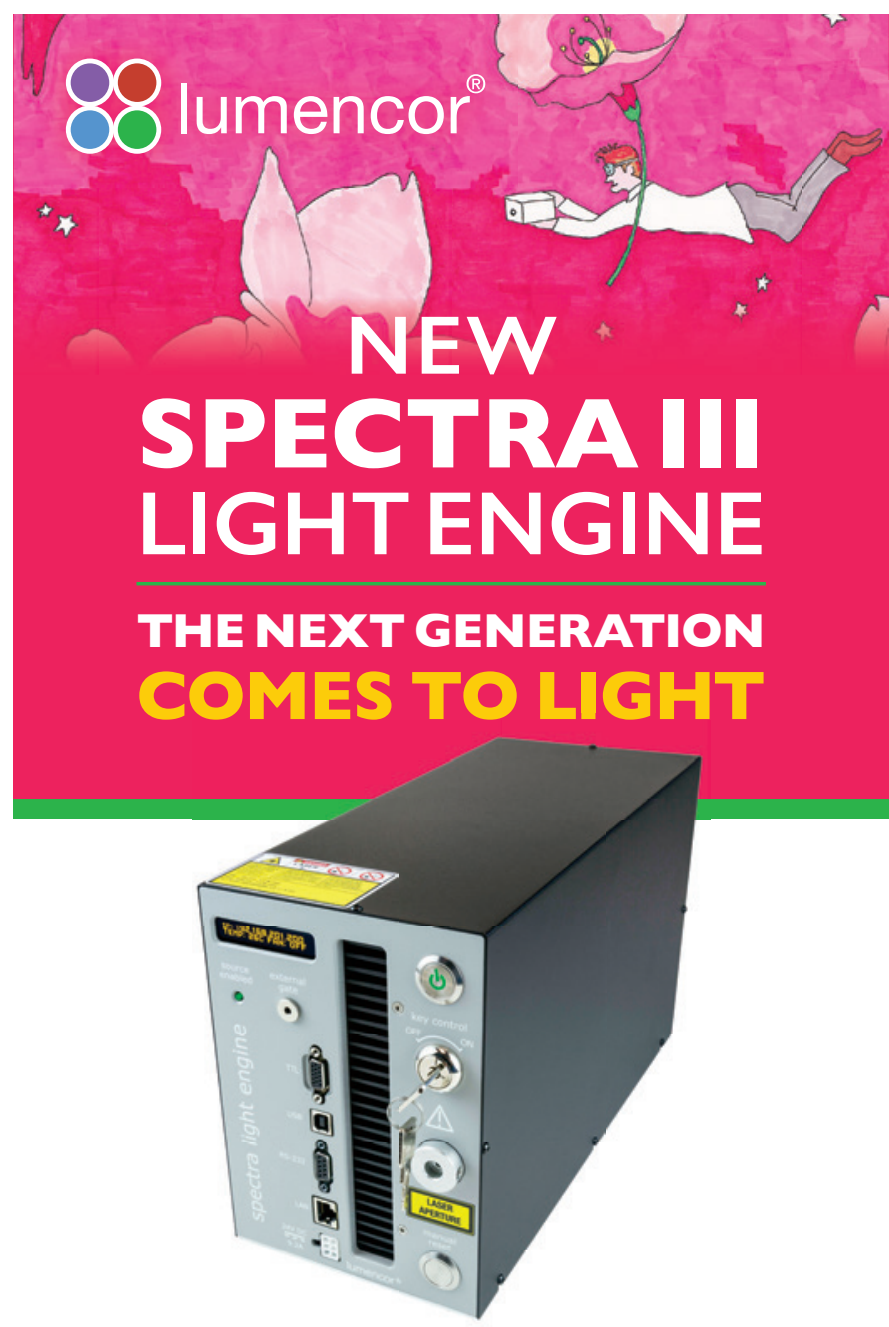

- Breadth: Eight spectrally optimized sources for DAPI, CFP, GFP, YFP, Cy3, mCherry, Cy5, Cy7 excitation

- Power: $\sim 500 \mathrm{~mW} /$ output, $\sim 4 \mathrm{~W}$ total

- Control: Exceptional power and wavelength stability

- Stability: Exceptional reproducibility

- Ideal for quantitation

- Ease of use: Small, cool, pre-aligned, Mercury-Free

-Applications: Fluorescence microscopy among others, OEM customization upon request

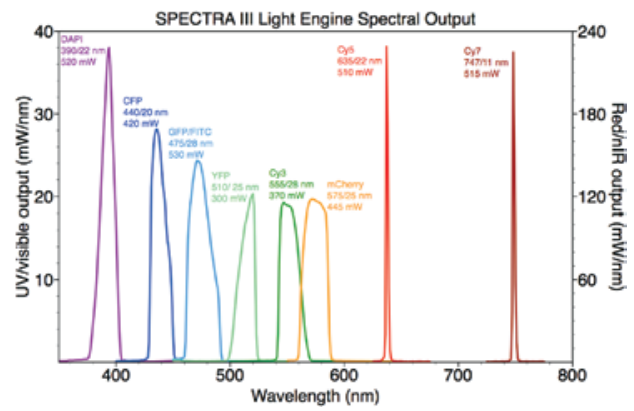

www.lumencor.com 